\title{
Aberrant expression of serotonin receptors in an aldosterone- and cortisol-producing adenoma
}

Lytrivi M.', Brisbois D.', Corvilain B. ${ }^{1}$, Demetter P.', Duparc C. ${ }^{3}$, Garcia C. ${ }^{2}$, Lefebvre H. ${ }^{3}$, Louiset E. ${ }^{3}$, Lucidi V.', Moreno-Reyes R. ${ }^{1}$, Wils J. ${ }^{3}$, Driessens N.

Université Libre de Bruxelles, Erasme University Hospital, Brussels, Belgium ${ }^{2}$ Bordet Hospital, Brussels, Belgium ${ }^{3}$ INSERM U982, University of Rouen, France

\section{INTRODUCTION}

Aberrant expression of serotonin receptors has been described to be involved in the pathophysiology of both aldosterone-producing and cortisol-producing adrenal adenomas.

\section{CASE REPORT}

A 46-year-old woman was referred for evaluation of severe hypertension associated with hypokalemia. No clinical features of overt hypercortisolism were present. The initial hormonal work-up after discontinuation of interfering antihypertensive drugs and correction of hypokalemia showed:

\begin{tabular}{|c|c|c|c|}
\hline & & $\begin{array}{l}\text { Reference } \\
\text { range }\end{array}$ & \\
\hline Aldosterone (pg/ml) & 213 & $40-310$ & 7 \\
\hline $\operatorname{Renin}(\mu \mathrm{U} / \mathrm{ml})$ & $<2.0$ & 3.0-45 & - Positive aldosterone/renin ratio \\
\hline $\begin{array}{l}\text { Aldosterone/renin } \\
{[(\mathrm{pg} / \mathrm{ml}) /(\mu \mathrm{U} / \mathrm{m})]}\end{array}$ & $>40$ & $<24$ & Positive aldosterone/renin ratio \\
\hline $\begin{array}{l}\text { Cortisol (ng/ml) } \\
\text { АCTH (pg/ml) }\end{array}$ & & 10-48 & Suppressed ACTH \\
\hline DHEA-s $(\mathrm{ng} / \mathrm{ml})$ & 200 & $900-3500$ & $\longleftarrow$ Low DHEA-s concentration \\
\hline $\begin{array}{l}\text { Morning cortisol post 1-mg } \\
\text { dexamethasone suppression test } \\
(\mathrm{ng} / \mathrm{ml})\end{array}$ & 28 & $<18$ & $\longleftarrow$ Abnormal LDDST \\
\hline
\end{tabular}

Subsequent confirmatory tests were performed:
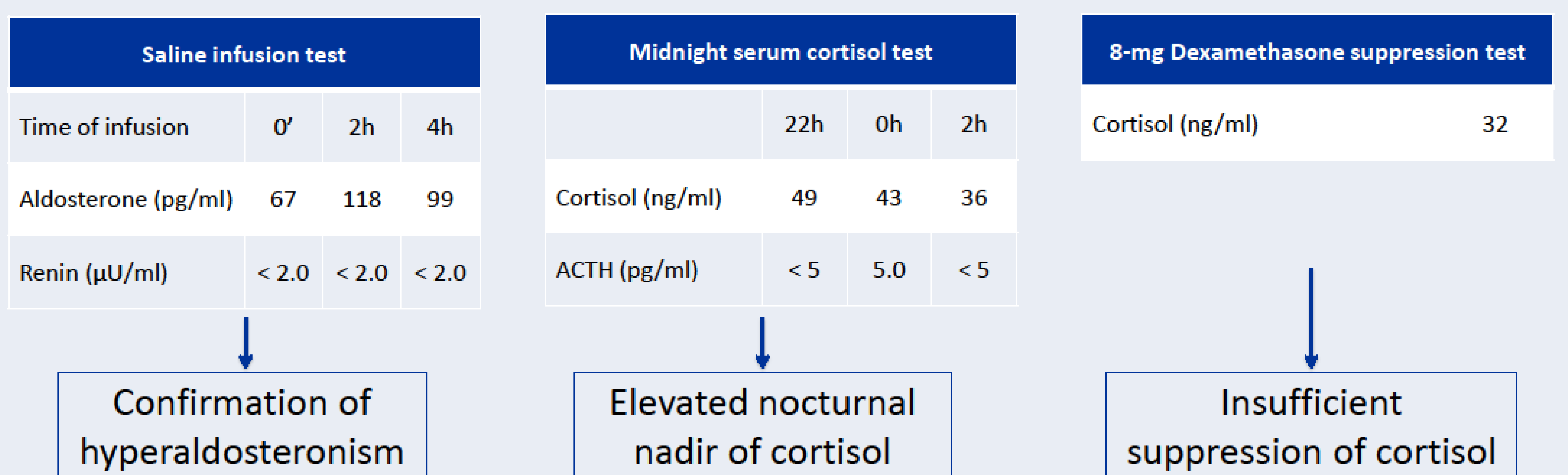

Based on the conjunction of these results, primary hyperaldosteronism with concurrent subclinical Cushing's syndrome was diagnosed.

A CT-scan demonstrated a lesion of $4 \mathrm{~cm}$ in the right adrenal gland and a second lesion of $1 \mathrm{~cm}$ in the left adrenal gland, both displaying an adenoma imaging phenotype.

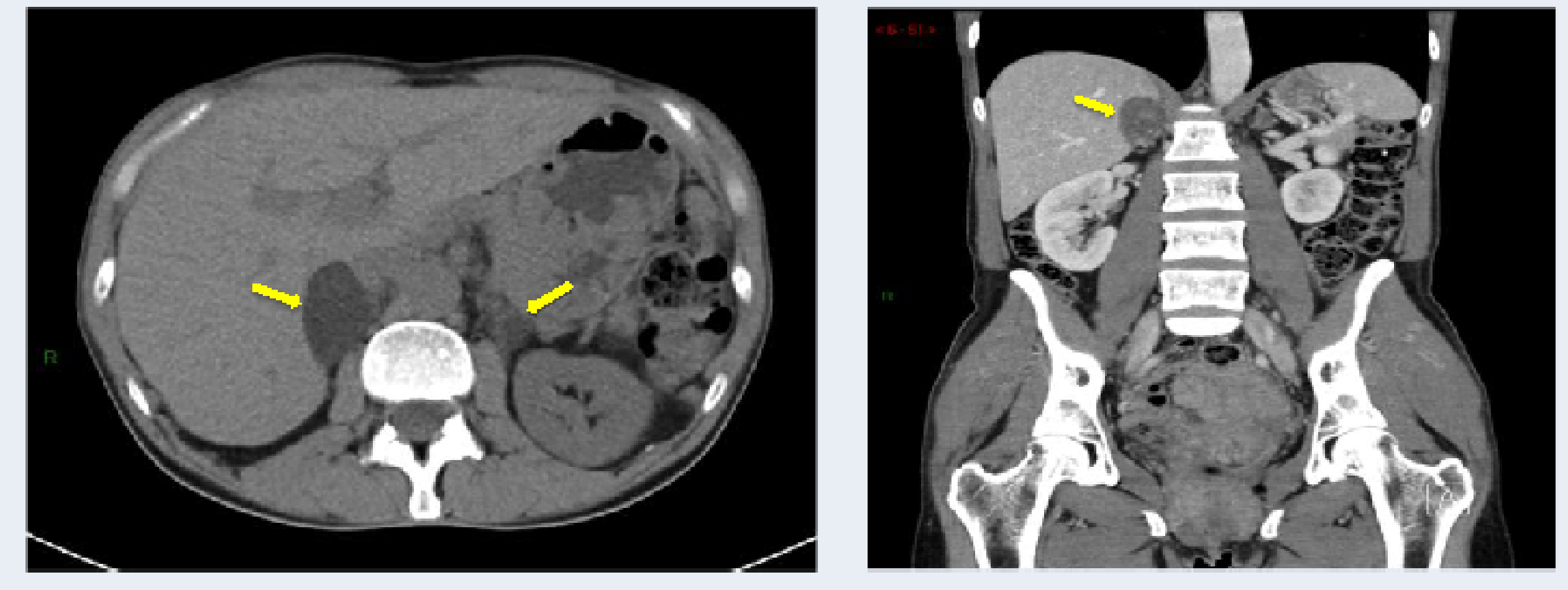

Abdominal CT scan showing bilateral adrenal masses. Both lesions have unenhanced attenuation values $<10 \mathrm{HU}$.

We then explored the potential aberrant expression of serotonin receptors in the adrenal cortex by intravenous (IV) administration of metoclopramide, a serotonin type 4 receptor $\left(5-\mathrm{HT}_{4}-\mathrm{R}\right)$ agonist, following dexamethasone (DXM) suppression of adrenal steroidogenesis.
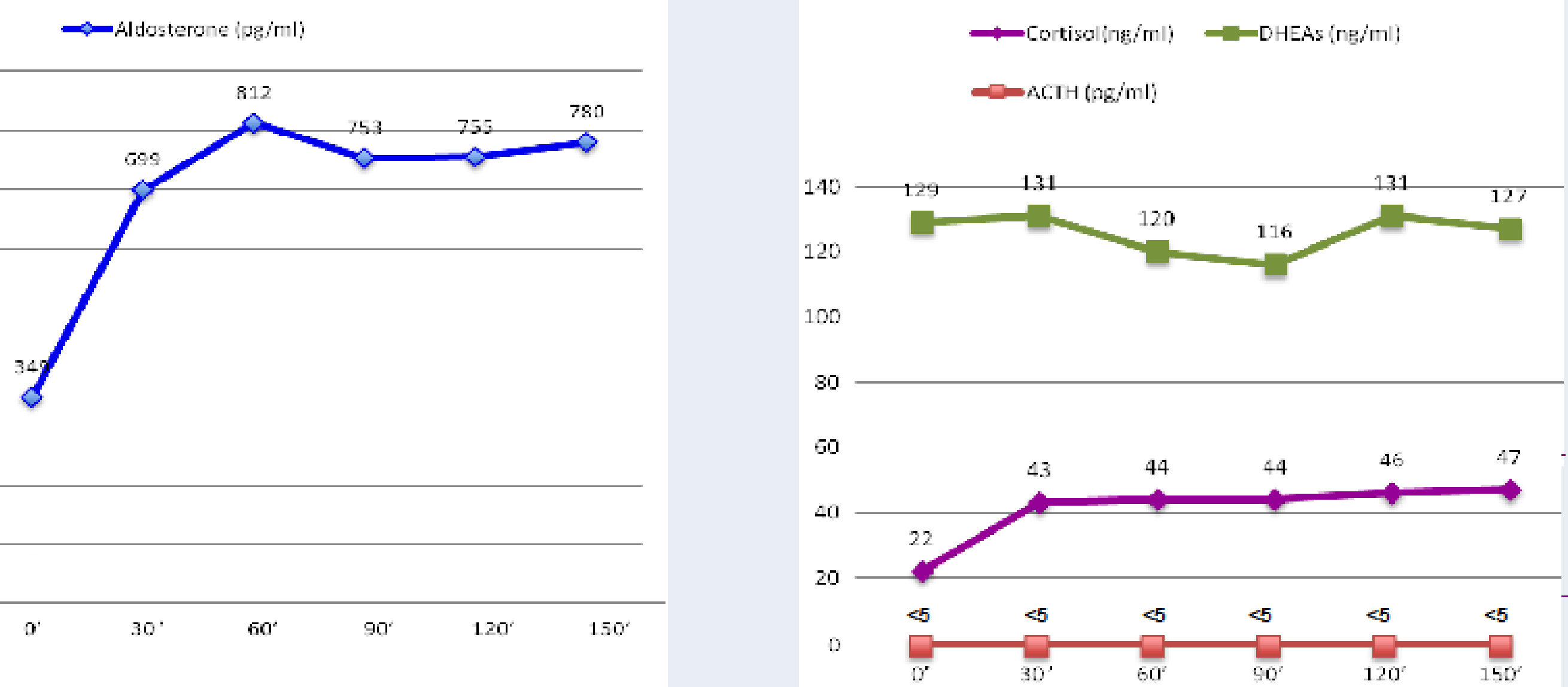

Abnormal cortisol increase after injection of metoclopramide, under DXM suppression

We noted a clearly abnormal cortisol increase in peripheral blood after metoclopramide injection. An increase of aldosterone was also observed. This latter increase occurs in normal individuals but no cut-off of supra-physiological response exists.

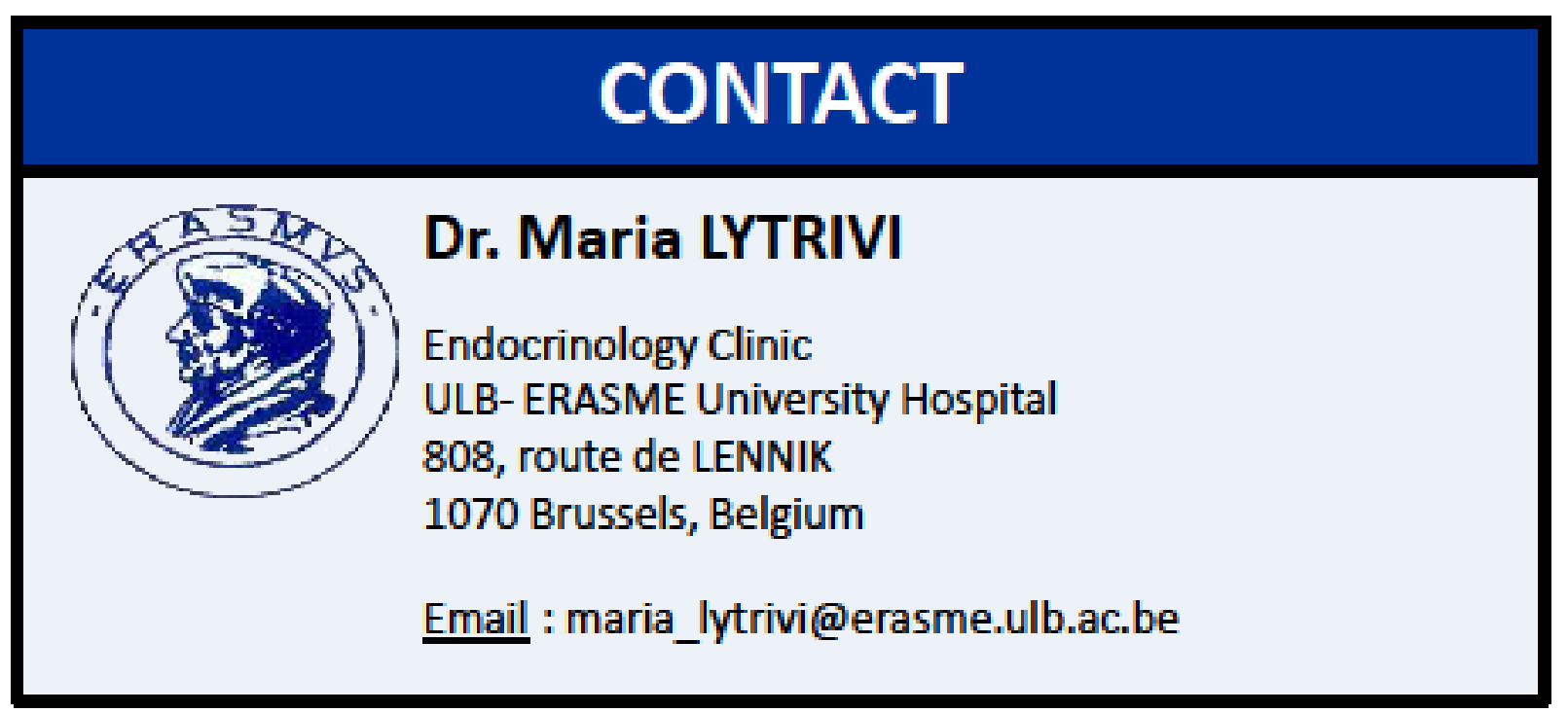
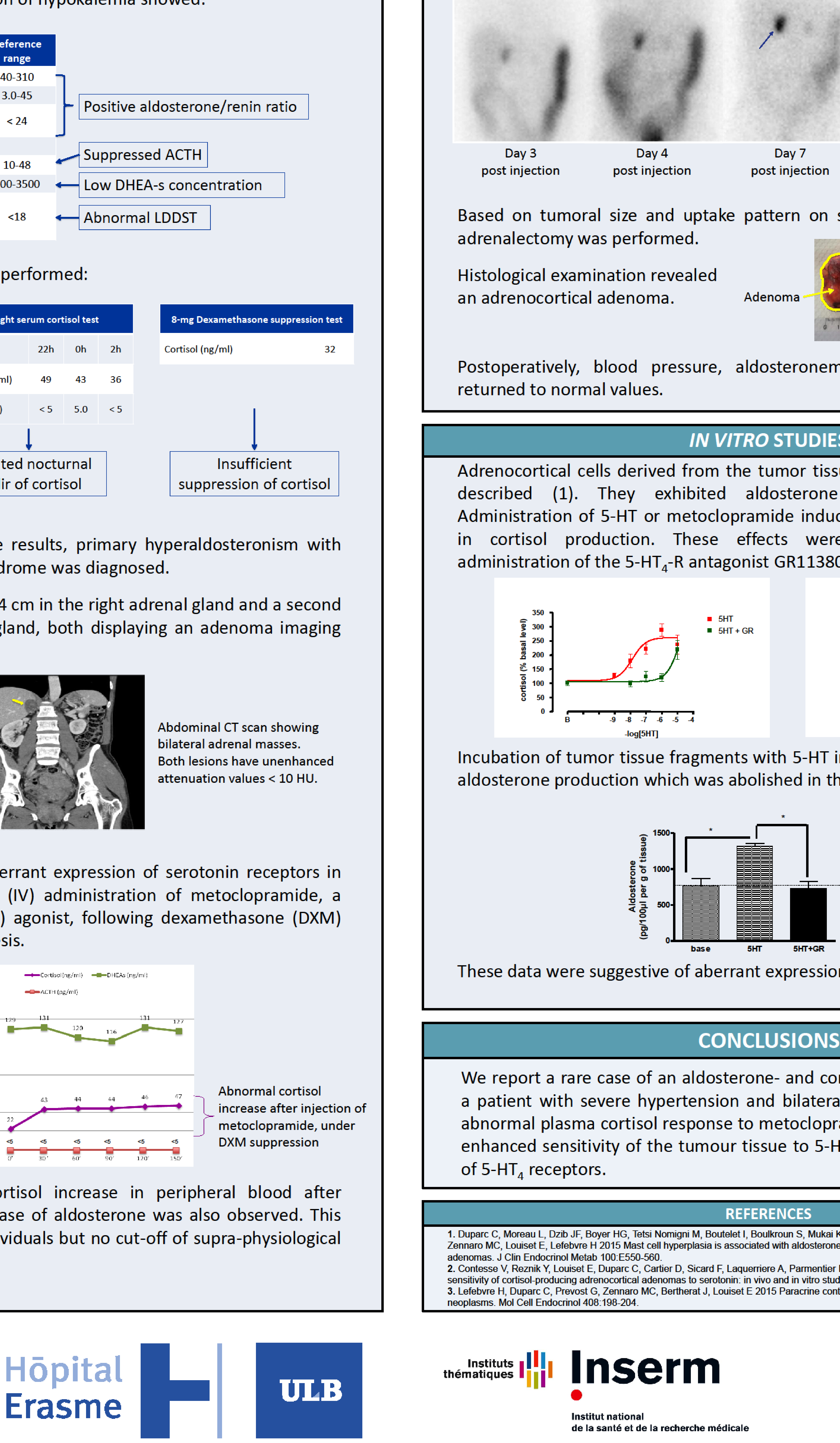

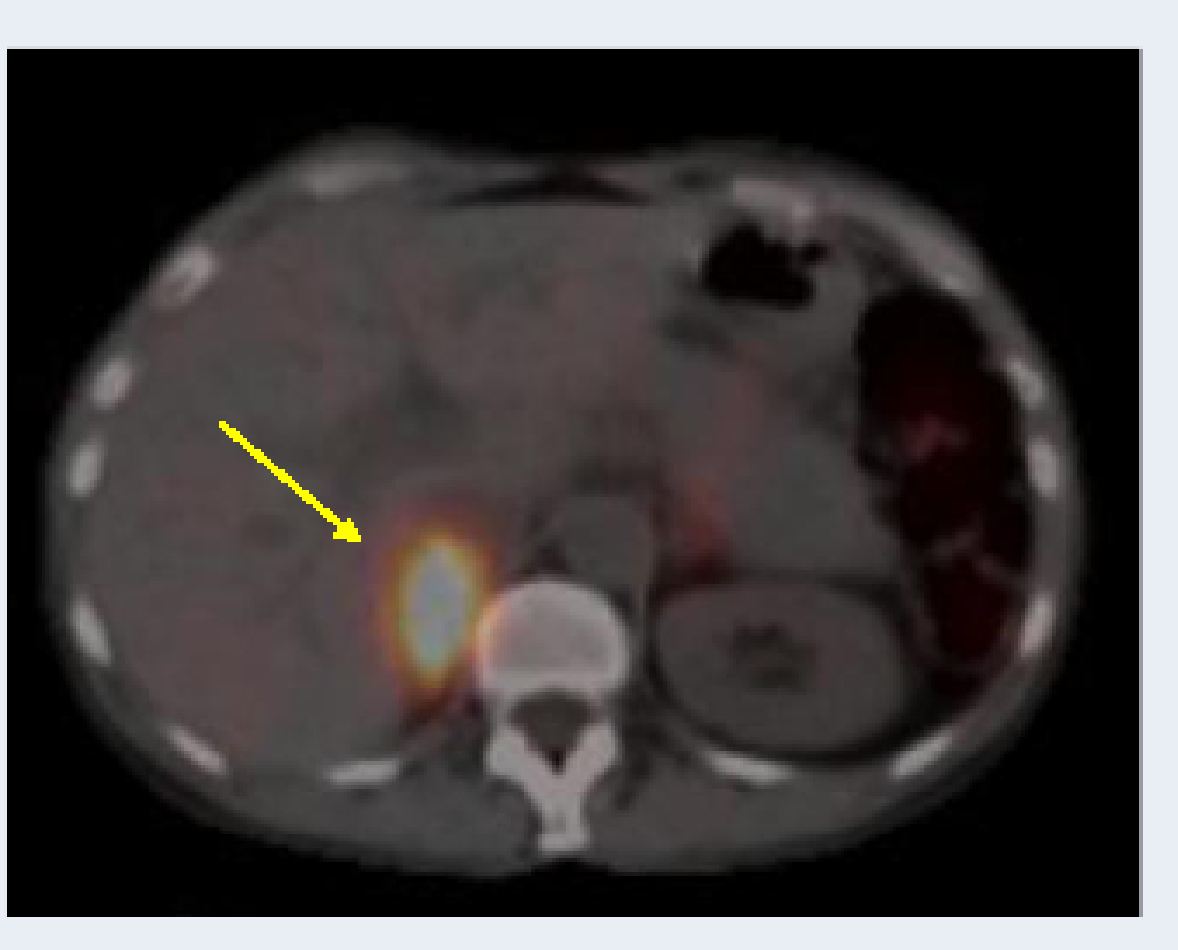

Fused SPECT/CT image
Based on tumoral size and uptake pattern on scintigraphy, right laparoscopic adrenalectomy was performed.

Histological examination revealed an adrenocortical adenoma.

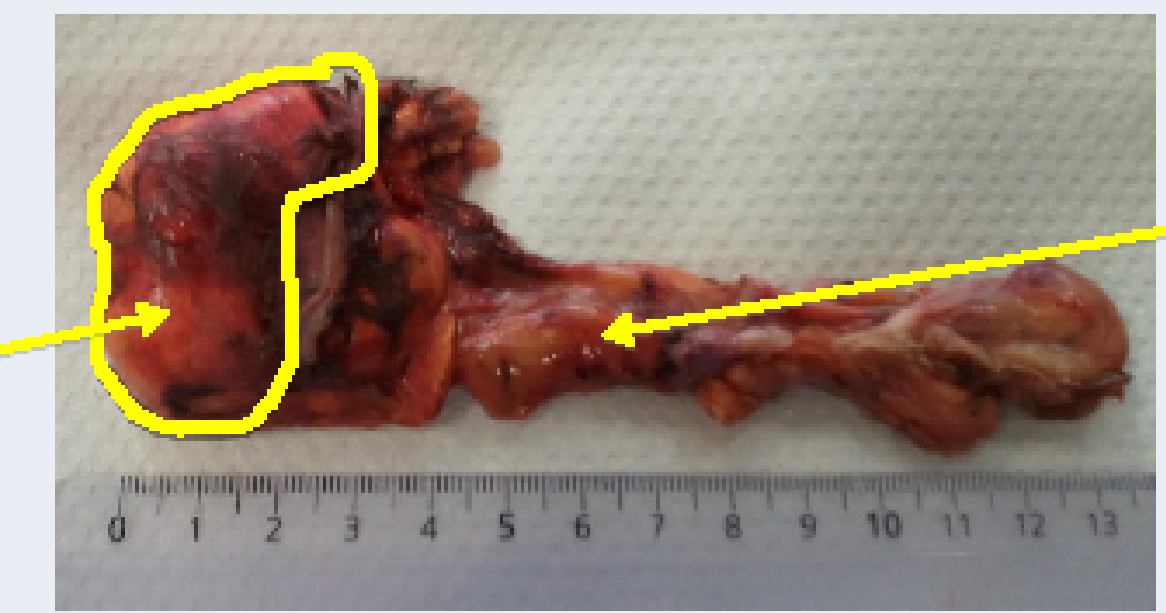

Postoperatively, blood pressure, aldosteronemia and free urinary cortisol returned to normal values.

\section{IN VITRO STUDIES}

Adrenocortical cells derived from the tumor tissue were cultured as previously described (1). They exhibited aldosterone and cortisol co-secretion. Administration of 5-HT or metoclopramide induced a dose-dependent increase in cortisol production. These effects were inhibited by concomitant administration of the $5-\mathrm{HT}_{4}-\mathrm{R}$ antagonist $\mathrm{GR} 113808$
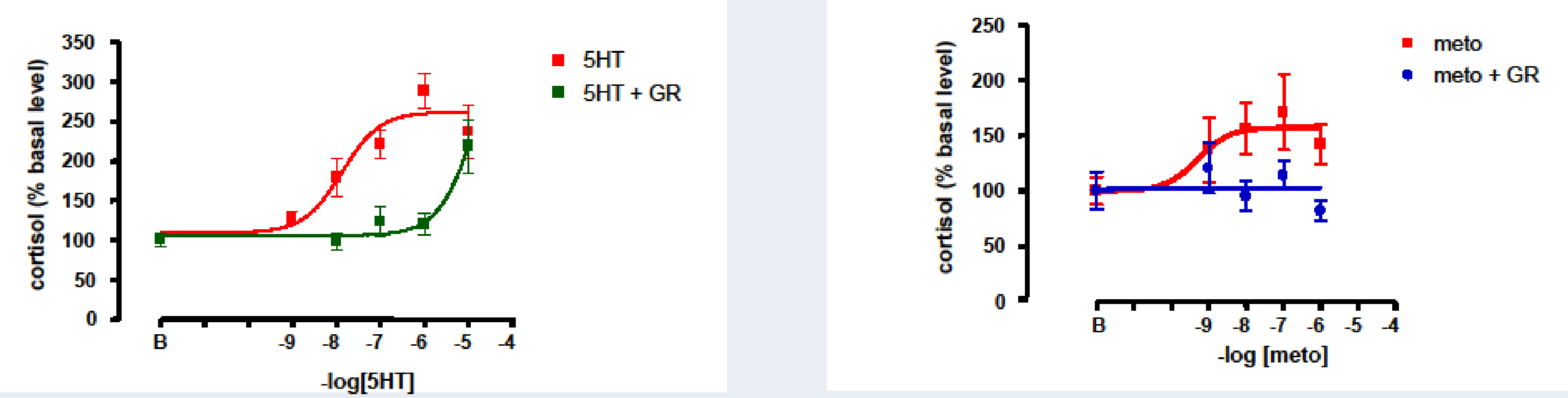

Incubation of tumor tissue fragments with 5-HT induced a significant increase in aldosterone production which was abolished in the presence of GR113808.

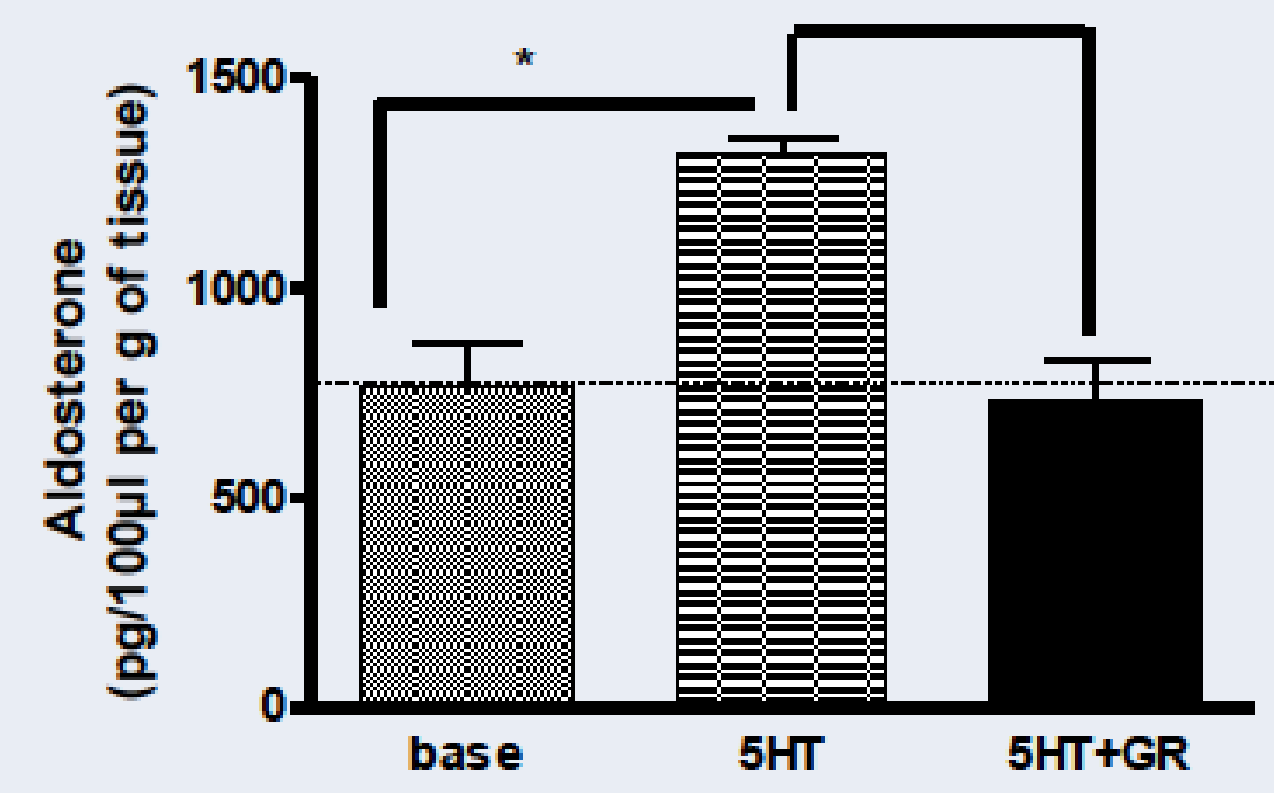

These data were suggestive of aberrant expression of $5 \mathrm{HT}_{4}-\mathrm{R}$ in the tumor tissue.

\section{CONCLUSIONS}

We report a rare case of an aldosterone- and cortisol-co-producing adenoma in a patient with severe hypertension and bilateral adrenal masses exhibiting an abnormal plasma cortisol response to metoclopramide. In vitro studies revealed enhanced sensitivity of the tumour tissue to $5-\mathrm{HT}$ indicative of illicit expression of $5-\mathrm{HT}_{4}$ receptors.

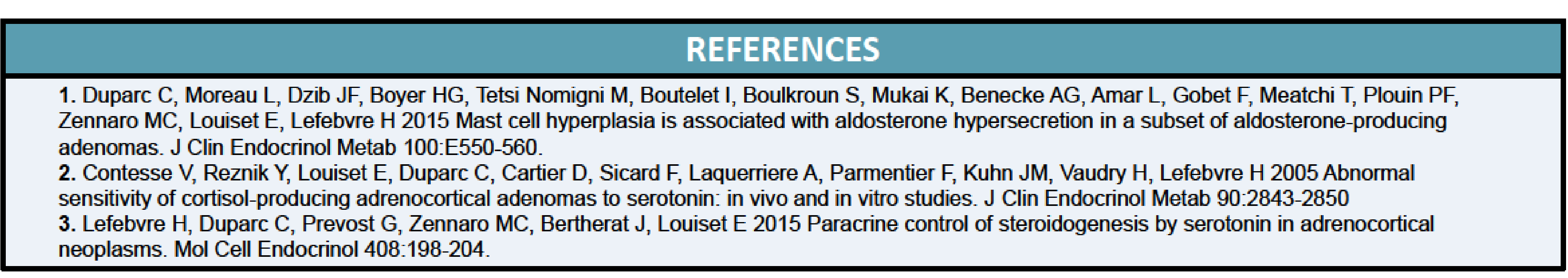

inmematitutus InI Inserm

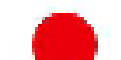

UNIVERSITÉ DEROUEN 